\title{
A systematic review of viewing conditions and monitor specifications in mammography
}

\section{ABSTRACT \\ Objectives}

The purpose of this systematic review was to establish the current status of recommended monitor specifications and viewing conditions in mammography for image acquisition and reporting rooms. A literature search was completed between August 2018 and March 2019 using ScienceDirect, PubMed, Web of Science and MEDLINE databases. An additional manual search was performed to identify relevant guidelines to support the review. Only articles and guidelines written in English were included.

\section{Key Findings}

Results were selected according to the following criteria; articles detailing (i) monitor specification and, (ii) viewing conditions in mammography acquisition and reporting rooms. Twenty-one studies met the inclusion criteria. Six papers described monitor specifications, five described viewing conditions and ten guideline documents were identified from the UK, Europe and the US. Common outcomes were that monitors with 3 or 5 MP resolution seemed to be preferred and at the same time higher illumination levels ( $>15$ lux) were found to decrease the luminance of the monitors and negatively impact the assessment of image quality. Contrary to this, the majority of guideline documents recommended illumination levels above 20 Lux. Finally, there is a lack of guidance for viewing conditions in acquisition rooms.

\section{Conclusion}

This review did not reveal any strong evidence for the proposed room illumination levels in acquisition rooms. In reference to monitors specifications, there is preference for using higher resolution displays ( 3 and $5 \mathrm{MP}$ ) but again, the evidence is not strong. Moreover, variance exists in the guidelines and that promotes inconsistency in mammography departments.

\section{Implications for practice}

This review highlights the lack of standarised guidelines and the need for further research on the viewing conditions and monitor specifications for the acquisition rooms in mammography. 


\section{Introduction}

Monitor specification and viewing conditions are of great importance in radiology and can have an impact on overall diagnostic performance. ${ }^{1}$ Using lower specification monitors and completing tasks in a sub-optimal environment may have a negative impact on image quality appraisal and the detection of pathology.

Many technical factors contribute to image quality and there has been a heavy focus on the technology used to produce full field digital mammograms (FFDM). ${ }^{2}$ However, monitor specification and environmental conditions can be dominant influences in overall image quality and there is currently no comprehensive review of the current standards in mammography available in the literature. ${ }^{1}$ The primary aim of this systematic review was to evaluate all scientific evidence on the recommended monitor specifications and viewing condition for mammography image review in both acquisition and reporting rooms. These images evaluation tasks completed in these rooms are different but of equal importance as in the acquisition rooms the assessment of the technical quality of the image takes place and in the reporting rooms the diagnosis is made. A sub-optimal evaluation of image quality in the acquisition room could lead to difficulties in diagnosis or a recall of the patient. A secondary aim is to describe all guideline documents still in operation and evaluate the recommendations in relation to the scientific evidence from the systematic review of scientific literature.

\section{Materials and Method}

\section{Search Strategy}

The literature search was completed between August 2018 and March 2019 using ScienceDirect, PubMed, Web of Science and MEDLINE; only papers written in English were included in this search. The following key words were included in this review; 'mammography', 'image quality', 'ambient lighting', 'monitors', and 'viewing conditions'. Boolean operators (AND, OR, NOT) were used to refine the data retrieved during searching. The initial search identified 415 primary research articles. Additionally, a manual search of guidelines for monitor specification and viewing conditions was performed on the websites of seven relevant regulatory and advisory bodies. The references from the identified documents were also examined for additional eligible studies and six additional articles were obtained. In total 421 resources were identified.

\section{Eligibility Criteria for Study Selection}

With the exception of the guidelines, only peer-reviewed papers were included. The PRISMA flow diagram (Figure 1) explains the screening process. Of the 421 articles from the databases, 11 met the inclusion criteria. 92 articles were excluded as duplicates, 218 articles were excluded from the misleading titles and finally 100 articles were excluded as the abstract was not relevant to the question posed for this systematic review. 
In the search of guidelines, seven different organisations in United Kingdom ( $n=3)$, Europe $(n=1)$, America $(n=2)$ and one Internationally, were examined (Table 1). The evaluation of the identified documents in the regulatory bodies performed by examining the guidelines in force. Out of this search 10 documents relevant to this search were identified. In total, 21 articles and guideline documents found suitable for this review.

Table 1:Regulatory bodies and guideline documents in the systematic review. The documents are categorised according the country of origin and the year of publication.

\begin{tabular}{l|l|l|l}
\hline Organisation & Country & Title & Year \\
\hline $\begin{array}{l}\text { Institute of Physics } \\
\text { and Engineering in } \\
\text { Medicine }\end{array}$ & $\begin{array}{l}\text { United } \\
\text { Kingdom }\end{array}$ & $\begin{array}{l}\text { Recommended standards for the routine } \\
\text { performance testing of diagnostic x-ray } \\
\text { imaging system }\end{array}$ & 2005 \\
\hline $\begin{array}{l}\text { National Health } \\
\text { System Breast } \\
\text { Screening Programme }\end{array}$ & $\begin{array}{l}\text { United } \\
\text { Kingdom }\end{array}$ & $\begin{array}{l}\text { Guidance on image display equipment for } \\
\text { use in breast screening }\end{array}$ & 2010 \\
\hline $\begin{array}{l}\text { The Royal College of } \\
\text { Radiologists }\end{array}$ & $\begin{array}{l}\text { United } \\
\text { kingdom }\end{array}$ & $\begin{array}{l}\text { Picture archiving and communication } \\
\text { systems (PACS) and guidelines on } \\
\text { diagnostic display devices, second edition }\end{array}$ & 2013 \\
\cline { 2 - 4 } & \begin{tabular}{l} 
35 Audit of reporting room illumination \\
\cline { 2 - 4 }
\end{tabular} & $\begin{array}{l}\text { Picture archiving and communication } \\
\text { systems (PACS) and guidelines on } \\
\text { diagnostic display devices, third edition }\end{array}$ & 2013 \\
\hline $\begin{array}{l}\text { European Reference } \\
\text { Organisation for } \\
\text { Quality Assured } \\
\text { Breast Screening and } \\
\text { Diagnostic Services }\end{array}$ & Europe & $\begin{array}{l}\text { European protocol for the quality control } \\
\text { of the physical and technical aspects of } \\
\text { mammography screening }\end{array}$ & 2006 \\
\cline { 2 - 4 } & $\begin{array}{l}\text { European guidelines for quality assurance } \\
\text { in breast cancer screening and diagnosis }\end{array}$ & 2013 \\
\hline $\begin{array}{l}\text { American Association } \\
\text { of Physics in Medicine }\end{array}$ & USA & $\begin{array}{l}\text { Assessment of display performance for } \\
\text { medical imaging systems: executive } \\
\text { summary of AAPM TG18 report }\end{array}$ & 2005 \\
\hline $\begin{array}{l}\text { American College of } \\
\text { Radiology }\end{array}$ & USA & $\begin{array}{l}\text { Acr-Aapm-Siim Technical standard for } \\
\text { electronic practice of medical imaging }\end{array}$ & 2017 \\
\hline $\begin{array}{l}\text { International Atomic } \\
\text { Energy Agency }\end{array}$ & Globally & $\begin{array}{l}\text { Quality assurance programme for digital } \\
\text { mammography IAEA 2011 }\end{array}$ & 2011 \\
\hline
\end{tabular}

\section{Data collection and quality assessment}

The data extraction included the following parameters: a) the publication year, b) the study design, c) the number of images evaluated, d) the number of observers reading the mammograms, e) the number of malignant and benign lesions (for audits and observer studies), f) ambient light levels, g) the type of analysis used in the studies. The quality of the identified studies and the likelihood of bias were assessed using the Quality Assessment of Diagnostic Accuracy Studies (QUADAS) tool. ${ }^{[3-4]}$ No papers were excluded from the review on this basis. 


\section{Study Design and Reporting}

Of the 421 search results from the database search, 21 met the inclusion criteria and thus were suitable for this review (Figure 1). Six articles were identified on monitor specifications, five on viewing conditions and 10 guideline documents were discovered via a manual search. Of the 11 articles, 8 were experimental quantitative studies and 3 were commentary articles. The most frequent publication location was The British Journal of Radiology $(n=2)$. The remaining articles were retrieved from 6 different journals, 2 conferences and 1 organisational website. The majority of studies were performed in the United States $(n=5)$, United Kingdom ( $n=4)$ with one each from The Republic of Ireland and Australia.

\section{Results}

The search of literature was not restricted by publication date and the articles included in this review were published from 2003 to 2017 . The reason for the relatively large date range is the lack of recent publications in this area specific to mammography. Again, the manual search of regulatory and professional bodies was not date restricted and the date of publication ranged from 2005 to 2019. Only documents that are still in operation were selected and evaluated.

It was frequent for papers that evaluated monitors to compare them on the basis of resolution; in some instances, this was comparing low resolution (1-2 MP) and high resolution $(5 \mathrm{MP}) .^{[2,5]}$ The evaluation on monitor specifications and technical characteristics was performed in three studies. ${ }^{[2,6-7]}$ At the same time, with reference to viewing conditions, most of the papers evaluated different ambient light levels and viewing conditions and the surrounding reflections on the monitor surface. ${ }^{[8-12]}$ Data on monitors specifications in acquisition and reporting rooms in mammography were provided by six eligible guideline documents. ${ }^{[12-17]}$ Data on viewing conditions for acquisition and reporting rooms in mammography were provided by ten guideline documents. ${ }^{[12-21]}$ The results of this search were divided in five domains: a) articles addressing monitor specifications, b) articles addressing different resolution monitors, c) classification of monitors according to guidelines, d) articles addressing viewing conditions and e) guidelines on viewing conditions.

In these studies, the number of observers involved in interpretation tasks ranged from of 628 . In the studies on monitor specifications, the number of observers reading mammograms was provided in four studies. ${ }^{[2,5,7,22]}$ At the same time, in the studies on viewing conditions, the number of observers was provided in two studies. ${ }^{[11-12]}$ 

Figure 1: Identification process of literature search

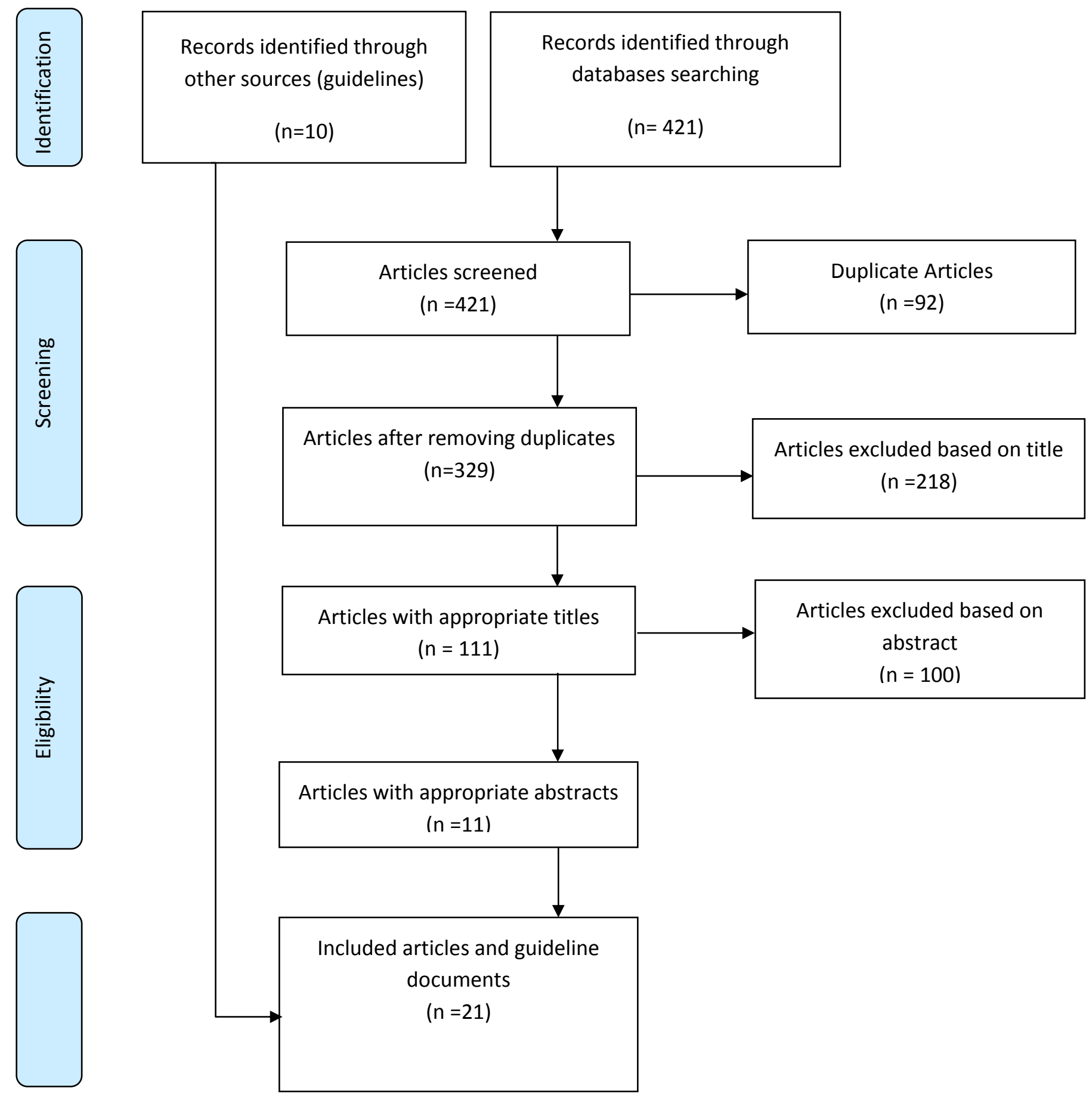




\section{Articles addressing monitor specifications}

During mammographic image evaluation, the most important parameters are the evaluation of the technical quality of the monitor and the environmental factors in the reporting and acquisition rooms. Brettle's commentary article summarised important factors as proper equipment, quality assurance, viewing conditions and the existing legislation for the mammographic image interpretation. ${ }^{6}$ At the same time, the majority of authors were in agreement that ambient lighting and monitor specification were important factors with potential impact on proper image assessment. ${ }^{[1,6]}$

\section{Articles addressing different resolution monitors}

The first comparison of monitors with different resolution came in 2011 by Ong et al. ${ }^{2}$ In this study the evaluation of the performance of low-resolution LCD monitors was performed using two different monitors. The first monitor had $3 \mathrm{MP}$ resolution and a panel size at 20.8 inches. The maximum luminance of this monitor was at $700 \mathrm{~cd} / \mathrm{m}^{2}$. The second monitor had lower resolution at 1.2 MP. The panel size of that monitor was at 19 inches and the maximum luminance was at $300 \mathrm{~cd} / \mathrm{m}^{2}$. The results of this study showed that there were no statistical and clinical difference between the two monitors. This study seemed statistically underpowered, with a large magnitude of intra-observer variability and a low number of cases (100 mammograms) and observers (8).

Chen et al examined the performance of monitors from a different perspective. ${ }^{7}$ They considered whether lower resolution devices could be used successfully to deliver image interpretation training. For that reason, they examined monitors with different resolutions and technical specifications, such as a medical workstation with 5 MP resolution, an LCD monitor with 1.8 MP resolution and an iPhone with 0.1 resolution. The results from this study showed that the radiologist's performance on reading mammograms was significantly higher on the mammography workstation when at the same time the lower resolution monitor combined with appropriate image manipulation software was capable in a training environment. They suggested no significant differences in observer performance so long as the interpretation of the mammographic images was performed by making the use of appropriate image manipulation tools such as window width and window level adjustment, magnification, zoom and pan.

Kinnear and Mercer compared the detection of image blur on two monitors with different resolution (1 MP and $5 \mathrm{MP}$ ) under viewing conditions where the room light level was adjusted to mimic the conditions of a reporting room. ${ }^{5}$ The result of this research showed that the ability of observers to detect image blurring on a $5 \mathrm{MP}$ monitor was better than that provided by a $1 \mathrm{MP}$ monitor. The study of Ma et al tended to agree with this and suggested that low resolution monitors are not suitable for the detection of blur. ${ }^{23}$ In this study the comparison took place between two monitors with different specifications and 2.3 and $5 \mathrm{MP}$ resolution respectively. It appeared that the monitor with $2.3 \mathrm{MP}$ resolution had poorer visual detection for blur and consequently higher technical recall rate than the higher resolution monitor. In total the $2.3 \mathrm{MP}$ monitor had 20.3\% technical recall rate, when the 5 MP monitor had only $9.1 \%$ technical recall rate. 


\section{Classification of monitors according to guidelines}

Six organisations (RCR, AAPM, EUREF, IAEA, NHSBSP, ACR) published guidelines between 2005 and 2019 on monitor specifications in mammographic units. The recommendations of the guidelines are summarised in Tables 4 and 5. Table 4 presents the monitors' optimum resolution in acquisition and reporting rooms according to regulatory bodies. Table 5 presents the monitors technical specifications according to the regulatory bodies' guidelines.

The guidelines from EUREF, IAEA and ACR have good agreement and recommend that in the acquisition rooms the workstation should be a $3 \mathrm{MP}$ monitor with $>250 \mathrm{~cd} / \mathrm{m}^{2}$ maximum luminance. ${ }^{14,16,17}$ For reporting rooms, a higher specification monitor is recommended, 5MP resolution with $>250 \mathrm{~cd} / \mathrm{m}^{2}$ maximum luminance. In contrast to this, AAPM suggest that the medical displays should be classified as 'secondary' monitors for acquisition room with 11.2MP optimum resolution and $>170 \mathrm{~cd} / \mathrm{m}^{2}$ maximum luminance. ${ }^{13} \mathrm{In}$ reporting rooms, the monitors and classified as 'primary' monitors and should have 3-5 MP resolution, with $>500$ $\mathrm{cd} / \mathrm{m}^{2}$ maximum luminance.

In 2010, NHSBSP proposed that the medical displays should be categorised as 'diagnostic', 'professional' and 'general' monitors. ${ }^{15}$ This identifies monitors according to the use of the display and the area it will be placed. For that reason, different specifications for each group were proposed. In the acquisition rooms the 'general' display is recommended to have low optimum resolution (1MP) with $400 \mathrm{~cd} / \mathrm{m} 2$ maximum luminance. Additionally, in the reporting rooms 'diagnostic' monitors should have $5 \mathrm{MP}$ resolution and $700 \mathrm{~cd} / \mathrm{m}^{2}$ maximum luminance. The use of professional monitors is narrowed on viewing images in assessment clinics and during surgeries. For this reason, the monitor should have 2-3 MP resolution and $700 \mathrm{~cd} / \mathrm{m}^{2}$ maximum luminance.

Finally, the last guidance comes from RCR. ${ }^{18}$ This professional body suggest that the monitors should be divided in two categories: a) clinical and mobile review display and b) breast radiology display. The clinical and mobile displays should have optimum resolution 2 $\mathrm{MP}$, maximum pixel pitch $0.250 \mathrm{~mm}$ and the luminance of the monitor should be $\leq 250$ $\mathrm{cd} / \mathrm{m}^{2}$. The breast radiology displays should have $5 \mathrm{MP}$ resolution, $0.17 \mathrm{~mm}$ pixel pitch and luminance $\leq 400 \mathrm{~cd} / \mathrm{m}^{2}$.

\section{Articles addressing viewing conditions}

The evaluation of monitor specification suggested that the resolution, the contrast ratio and the brightness are the main characteristics that can influence the perception of image quality. Apart from those technical characteristics the position of the monitor in relation to natural and artificial light sources is as important as the overall ambient light in the acquisition and reporting room. ${ }^{8} \mathrm{~A}$ high ambient light level decreases the luminance of the monitor through reflection. Reduced monitor brightness decreases the accuracy of image assessment and there is also an associated increase in interpretation time. ${ }^{8}$ Moreover, the placement of monitors used for radiological viewing is important in order to try and minimise the reflections that can occur. ${ }^{9}$ As a consequence, the impact of different levels of ambient light were examined. 
The first study demonstrating the effect of different ambient light levels on mammographic image interpretation came by Chakrabarti. ${ }^{10}$ Chakrabarti concluded that high ambient light (>15lux) had a damaging effect on image quality, mainly when the surrounding monitor luminance (i.e. not the target area of interest) is $0-5 \%$ of the maximum. The surrounding area is the area around the target image and it appeared that variances in luminance levels in that area affect image interpretation. All the observers noted that when the ambient light is increased their ability to discern low-contrast objects decreased.

The range of luminance levels to which the human eyes can adapt while viewing a mammogram and the effect of increased ambient lighting on the detection of subtle objects on medical images were examined by Pollard et al. Their results showed that the luminance level to which the eyes adapt lies between 12 and $20 \mathrm{~cd} / \mathrm{m}^{2}$, leading to an optimum reading room illuminance of approximately 50-80 lux. In addition, they implied that the ambient light within this range potentially improves radiologist comfort without harmful effects on diagnostic performance. ${ }^{12}$

Finally, the same team a year later, evaluated the ambient light levels in a mammography reporting room in relation to observer's performance of lesion detection in breast imaging. ${ }^{11}$ Eighty-six mammograms were evaluated by four observers under two different ambient light levels. From this study it was concluded that an increase of ambient light was not statistically significant and further study is required. Three main limitations of the study were the number of observers, the overall number of the cases and the recall bias inherent to viewing images more than once. However, it is accepted that it is difficult to overcome some of these limitations in observer studies.

\section{Guidelines on viewing conditions}

Evaluation of current guidelines in use in United Kingdom (UK) and the United States of America (US), revealed some noteworthy deviations. The first document published by IPEM suggested the ambient light level should be above 15 lux. ${ }^{19}$ On the contrary AAPM suggested the ambient light level should be in the range of 2-10 lux. ${ }^{13}$ In the same document, the importance of diminishing light reflections from direct light sources such as ceiling lights, film illuminators, surgical lamps or bright wall colours is mentioned.

A year later, EUREF suggested that the ambient light level should be less than 10 lux while underlining the fact that the overall ambient light conditions are dependent on the reflection characteristics and the maximum luminance of the monitor. ${ }^{14}$ It is reported that the illumination levels can seriously affect the visible dynamic range and the visibility of low contrast structures and lesions. A few years later, NHSBSP suggested that the high levels of ambient light should be avoided. ${ }^{15}$ There is no definition in the document of the high level or how to achieve this.

In 2011 the international organisation IAEA suggested that the ambient light level in rooms should be 20-40 lux, with a preference at 30 lux. ${ }^{16}$ Furthermore, it was also commented that illumination levels of 75-100 lux can be acceptable when it is confirmed that the light reflected toward the eyes of the radiologists is less than $1 / 250$ of the maximum luminance provided by full image brightness. In practice, this is difficult to assess and the only feasible 
solution is to have a good quality assurance programme in place. Reporting practitioners and the medical physicists should evaluate test pattern under different conditions to ensure a stable and consistent working environment. In the same document it is proposed that the wall colour in the rooms should be the same intensity as a mid-grey background on the screen. It is stated that the reflected light from the walls should be similar to the brightness emanating from the monitor when a grey image is displayed ( $\approx 30 \%$ of full image brightness).

In the next two years, two documents were published from RCR. ${ }^{21,22}$ In these documents there is further mention of the importance of low reflectivity paint (non-white) on walls in reporting rooms, in order to reduce the light reflection, when at the same point a low ambient light level of 15 lux is proposed.

In 2013, EUREF proposed that the ambient light level should be $\leq 20$ lux for LCD monitors and $\leq 10$ lux for CRT monitors while the ACR suggested ambient light levels should be in the range of 25-50 lux. ${ }^{20}$ It was proposed that at these levels the specular and diffuse reflection on the monitor's screen is minimised. It is anticipated that this should minimize eyestrain experienced by the reporting practitioners. Finally, the most recent published guideline comes from RCR. ${ }^{18}$ In this document it is mentioned that the ambient light level should be kept low but a level is not specified.

\section{Discussion}

This systematic review of the literature was performed to generate a depth of understanding about the current status of monitors and the optimal environment for image evaluation in mammography. While a preference for a higher resolution monitors has been demonstrated, there are some notable differences. Monitor specifications can be described by factors of: a) optimum resolution, b) the physical size of the display, c) contrast ratio, d) brightness, and e) the pixel pitch. These factors may provide an initial classification of monitors and a banding scheme can be created with five monitors bands ( $A+, A, B, C, D)$. Each band corresponds to monitors with different demands. The $A+$ is the monitor with the highest quality for demanding applications, mainly used in reporting mammograms. The $A$ is a high-quality monitor used in radiology conventional review. The $B$ is a reporting monitor with lower contrast or resolution. The $\mathrm{C}$ is a review monitor but not used for diagnosis. And finally the D monitor is used only for IT applications. ${ }^{6}$ As a result, it is clear that each monitor can be addressed in a specific clinical area and can have certain possibilities. For this reason, the monitor's comparison became important.

This systematic review reveals a preference for using higher resolution monitors (3-5 MP optimum resolution) in order to achieve better assessment of pathology and image quality. According to the majority of the identified articles, a monitor with 5MP optimum resolution had significantly better performance on image quality in relation to a low-resolution display. Additionally, in monitors with higher resolution better observers' accuracy can be achieved. The comparison among monitors with lower resolution such as 1 and $3 \mathrm{MP}$ showed no significant results. It appears that monitors with these resolutions performed similarly. Although the evidence is not strong enough as only four studies were found and illustrates 
no prevalence on monitor's specifications. It is clear that, the need of specialized research on the mammography field is required.

Evaluating the information provided by regulatory bodies (Tables 4 and 5 ), shows that there is inconsistency in recommendations for the acquisition rooms. In 2/6 of guideline documents the recommended monitors for the acquisition rooms is a $1 \mathrm{MP}$ display and in $4 / 6$ documents suggest a $3 \mathrm{MP}$ monitor. For the reporting rooms, 6/6 of the identified documents agreed that the monitor should have $5 \mathrm{MP}$ resolution. Only AAPM suggest that in reporting room the medical display can have 3-5 MP optimum resolution. Additionally, the colour of the walls and the reflections from the monitor screen were subjects under investigation. Matt finish paint and the position of the monitors in the rooms are important considerations but there is little in the way of guidance on how to achieve this. Furthermore, in the same documents, there is an apparent lack of consistency on viewing conditions and no specified viewing conditions specifically for the acquisition rooms. This is a difficult balance since the acquisition room needs to offer a suitable environment for the patient but also allow optimal evaluation of image quality.

The majority of guidelines proposes ambient light levels above 20 lux for reporting rooms but some regulatory bodies propose levels less than 20 lux. These contradictory results require further study as the ambient light level in the reporting and acquisition rooms is directly relevant to the diagnostic performance and technical evaluation of the mammographic images. In order to achieve strong evidence about the proper illumination level in these rooms further experimental work is necessary to create stronger evidence to support the guidance.

\section{Limitations}

A limitation of this review is the quantity and lack of current literature available on the topic of monitor specifications and viewing conditions in mammography. As such, many of the papers included are greater than 10 years old. Widening the search to include quality control and quality assurance in mammography may have revealed more papers, but this may also have further reduced the homogeneity of the data. The available data are heterogeneous and not entirely centered around the conditions and the devices for the acquisition room.

\section{Conclusion}

Monitor specifications and viewing conditions play a vital role in proper mammographic image assessment. Results from these research studies indicate that the use of poor quality monitors and illumination levels affect diagnostic accuracy. There is lack of solid research on monitor specifications and viewing conditions within mammography. At the same time the inconsistency and the contradictory guideline documents from the regulatory bodies may provoke non-conformity in clinical practice. Consequently, further research is required to achieve specific guidelines on monitors specifications and viewing conditions in mammography. 


\begin{tabular}{|c|c|c|c|}
\hline $\begin{array}{l}\text { Author, Year and } \\
\text { Reference No. }\end{array}$ & Purpose & Country & Findings/Conclusion \\
\hline $\begin{array}{l}\text { Chakrabarti et al, 2003, } \\
\text { [10] }\end{array}$ & $\begin{array}{l}\text { Effect of room illuminance on monitor black level } \\
\text { luminance and monitor calibration }\end{array}$ & USA & High ambient light reduced the image quality \\
\hline Puchalski S., 2006, ${ }^{[8]}$ & $\begin{array}{l}\text { Getting the most out of digital image viewing } \\
\text { digital viewing }\end{array}$ & USA & $\begin{array}{l}\text { High ambient light decreases the luminance of monitors. } \\
\text { Lower monitor brightness decreases the diagnosti } \\
\text { accuracy. }\end{array}$ \\
\hline Siegel et al, 2006, ${ }^{[1]}$ & $\begin{array}{l}\text { Digital Mammography Image Quality: Image } \\
\text { Display }\end{array}$ & USA & $\begin{array}{l}\text { Presentation of recommendations for mammographic } \\
\text { optimization }\end{array}$ \\
\hline Brettle D. S., 2007, ${ }^{[6]}$ & $\begin{array}{l}\text { Display considerations for hospital-wide viewing of } \\
\text { soft copy images }\end{array}$ & UK & $\begin{array}{l}\text { Five bands }(A+, A, B, C, D) \text { of monitors. Each band had it } \\
\text { specifications. } \\
\text { Ambient light level }>15 \text { lux }\end{array}$ \\
\hline Brennan et al, 2007, ${ }^{[9]}$ & $\begin{array}{l}\text { Ambient Light Levels for Radiological Soft Copy } \\
\text { Viewing: A Multi-Site Comparison }\end{array}$ & Ireland & $\begin{array}{l}\text { It was noticed a percentage of compliance to guidelines. } \\
\text { Proposed careful placement of monitors used for } \\
\text { radiological viewing }\end{array}$ \\
\hline Pollard et al, 2008, & $\begin{array}{l}\text { Object detectability under different ambient } \\
\text { lighting }\end{array}$ & USA & $\begin{array}{l}\text { The luminance level to which the eyes adapt better lies } \\
\text { between } 12 \text { and } 20 \mathrm{~cd} / \mathrm{m}^{2} \text {. The optimum reading room } \\
\text { illuminance should be } 50-80 \text { lux. }\end{array}$ \\
\hline Pollard et al, 2009, ${ }^{[11]}$ & $\begin{array}{l}\text { The Influence of Increased Ambient Lighting on } \\
\text { Mass Detection in Mammograms }\end{array}$ & USA & Increase of ambient light has not significant results \\
\hline Ong et al, 2011, ${ }^{[2]}$ & $\begin{array}{l}\text { Comparison of } 3 \mathrm{MP} \text { medical-grade to } 1 \mathrm{MP} \text { office- } \\
\text { grade } \mathrm{LCD} \text { monitors in mammographic diagnostic } \\
\text { and perceptual performance }\end{array}$ & Australia & No significant differences \\
\hline Chen et al, 2015, ${ }^{[7]}$ & $\begin{array}{l}\text { The use of lower resolution viewing devices for } \\
\text { mammographic interpretation: implications for } \\
\text { education and training }\end{array}$ & UK & $\begin{array}{l}\text { Better observer performance on the mammography } \\
\text { workstation. The lower resolution monitor combined with } \\
\text { manipulation software is capable for interpretation } \\
\text { training. }\end{array}$ \\
\hline
\end{tabular}




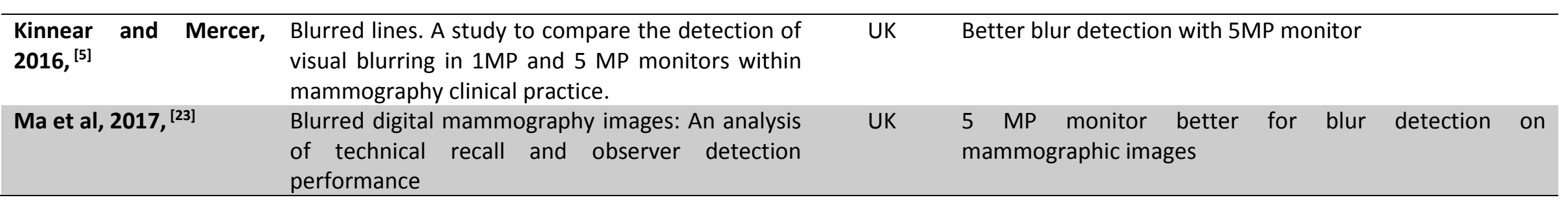

Table 3: Monitors in the systematic review

\begin{tabular}{|c|c|c|c|c|c|c|}
\hline Author & Type/Model & $\begin{array}{l}\text { Resolution } \\
\text { (MP) }\end{array}$ & Panel size (inches) & Contrast ratio & $\begin{array}{l}\text { Max. Luminance } \\
\left(\mathrm{cd} / \mathrm{m}^{2}\right)\end{array}$ & Pixel pitch (mm) \\
\hline \multirow[t]{2}{*}{ Ong et al } & Dome medical grey LCD & 3 & 20.8 & $600: 1$ & 700 & N/A \\
\hline & Dell SE198WFP LCD & 1.2 & 19 & 1000:1 & 300 & N/A \\
\hline \multirow[t]{3}{*}{ Chen et al } & GE Medical workstation & 5 & 21.5 & $\mathrm{~N} / \mathrm{A}$ & N/A & N/A \\
\hline & LCD monitor & 1.8 & 21.5 & $\mathrm{~N} / \mathrm{A}$ & $\mathrm{N} / \mathrm{A}$ & $\mathrm{N} / \mathrm{A}$ \\
\hline & iPhone 3 Apple & 0.1 & 3.5 & 201:1 & $\mathrm{N} / \mathrm{A}$ & N/A \\
\hline \multirow[t]{2}{*}{ Kinnear and Mercer } & EIZO & 5 & 21.3 & 1500:1 & 2000 & 0.165 \\
\hline & TOKOTU & 1 & 18.1 & $600: 1$ & 700 & N/A \\
\hline \multirow[t]{2}{*}{ Ma et al } & Multisync 243wm NEC & 2 & 24 & $\mathrm{~N} / \mathrm{A}$ & $\mathrm{N} / \mathrm{A}$ & 0.270 \\
\hline & DOME E5 NDS & 5 & 21.3 & $850: 1$ & 1100 & 0.170 \\
\hline
\end{tabular}


Table 4: Monitor's resolution for acquisition and reporting rooms according to guidelines

\begin{tabular}{|c|c|c|c|c|c|}
\hline \multirow{2}{*}{ Organisation } & \multicolumn{5}{|c|}{ Monitor's optimum resolution } \\
\hline & $1 \mathrm{MP}$ & $2 \mathrm{MP}$ & $3 \mathrm{MP}$ & $4 \mathrm{MP}$ & $5 \mathrm{MP}$ \\
\hline AAPM & $\checkmark$ & $\checkmark$ & $\checkmark$ & $\checkmark$ & $\checkmark$ \\
\hline EUREF & & & $\checkmark$ & & $\checkmark$ \\
\hline NHSBSP & $\checkmark$ & & & & $\checkmark$ \\
\hline IAEA & & & $\checkmark$ & & $\checkmark$ \\
\hline ACR & & & $\checkmark$ & & $\checkmark$ \\
\hline RCR & & $\checkmark$ & & & $\checkmark$ \\
\hline
\end{tabular}


Table 5: Guidelines on monitors' specifications included in the Systematic review

\begin{tabular}{|c|c|c|c|c|c|c|c|c|c|}
\hline $\begin{array}{l}\text { Organisation/ } \\
\text { Year }\end{array}$ & Country & Title & $\begin{array}{l}\text { Monitor's } \\
\text { Resolution } \\
\end{array}$ & $\begin{array}{l}\text { Panel size } \\
\text { (diagonal) }\end{array}$ & Contrast ratio & Viewing angle & $\begin{array}{l}\text { Brightness } \\
\left(\mathrm{cd} / \mathrm{m}^{2}\right)\end{array}$ & $\begin{array}{l}\text { Pixel } \\
(\mathrm{mm})\end{array}$ & pitch \\
\hline \multirow[t]{2}{*}{ AAPM / 2005} & US & $\begin{array}{l}\text { TG18 Assessment of display } \\
\text { performance for medical } \\
\text { imaging systems }\end{array}$ & $\begin{array}{l}\text { AR: } 1,2 \mathrm{MP} \\
1200 \times 1600\end{array}$ & N/A & N/A & $\begin{array}{l}>80^{\circ} \text { hor } \\
50^{\circ} \text { ver }\end{array}$ & 200 & N/A & \\
\hline & & & $\begin{array}{l}\text { RR: } 3,4-5 M P \\
1728 \times 2304 \\
2048 \times 2560\end{array}$ & $\mathrm{~N} / \mathrm{A}$ & N/A & $\begin{array}{l}>80^{\circ} \text { hor } \\
50^{\circ} \text { ver }\end{array}$ & 700 & $\mathrm{~N} / \mathrm{A}$ & \\
\hline \multirow[t]{2}{*}{ EUREF / 2006} & EUROPE & $\begin{array}{l}\text { European protocol for quality } \\
\text { control of the physical and } \\
\text { technical aspects of }\end{array}$ & AR:3MP & $\mathrm{N} / \mathrm{A}$ & N/A & N/A & 300 & N/A & \\
\hline & & mammography screening & RR: $5 \mathrm{MP}$ & $45-50 \mathrm{~cm}$ & N/A & N/A & 300 & $\mathrm{~N} / \mathrm{A}$ & \\
\hline \multirow[t]{2}{*}{$\begin{array}{l}\text { NHSBSP } \\
2010\end{array}$} & UK & $\begin{array}{l}\text { Guidance on image display } \\
\text { equipment for use un breast } \\
\text { screening }\end{array}$ & $\begin{array}{l}\text { AR: } 1 \mathrm{MP} \\
1280 \times 1024\end{array}$ & $43 \mathrm{~cm}$ & $600: 1$ & $160^{\circ}$ & 300 & 0,26 & \\
\hline & & & $\begin{array}{l}\text { RR: } 5 \mathrm{MP} \\
2048 \times 2560\end{array}$ & $50 \mathrm{~cm}$ & $600: 1$ & $170^{\circ}$ & 500 & 0,16 & \\
\hline \multirow[t]{2}{*}{ IAEA / 2011} & INTERNATIONAL & $\begin{array}{l}\text { Quality Assurance Programme } \\
\text { for Digital Mammography }\end{array}$ & AR: 3MP & N/A & $\geq 250: 1$ & N/A & N/A & N/A & \\
\hline & & & RR: 5MP & N/A & $\geq 250: 1$ & N/A & $\mathrm{N} / \mathrm{A}$ & N/A & \\
\hline \multirow[t]{2}{*}{ ACR / 2017} & AMERICA & $\begin{array}{l}\text { Technical Standard for } \\
\text { Electronic Practice of Medical }\end{array}$ & $\begin{array}{l}\text { AR: } 3 \mathrm{MP} \\
1500 \times 2000\end{array}$ & $52.5 \mathrm{~cm}$ & N/A & N/A & $\geq 250$ & $\begin{array}{l}0.250 \\
\leq 0.300\end{array}$ & \\
\hline & & Imaging & RR: 5MP & & & & $\geq 420$ & $\begin{array}{l}0,200 \\
\leq 0,210\end{array}$ & \\
\hline
\end{tabular}




\begin{tabular}{|c|c|c|c|c|c|c|c|c|}
\hline RCR / 2019 & UK & $\begin{array}{l}\text { Picture archiving and } \\
\text { communication systems (PACS) } \\
\text { and guidelines on diagnostic } \\
\text { display devices. Third edition }\end{array}$ & $\begin{array}{l}\text { AR: } 2 \mathrm{MP} \\
1600 \times 1200\end{array}$ & $\mathrm{~N} / \mathrm{A}$ & N/A & $\mathrm{N} / \mathrm{A}$ & $1-250$ & 0.250 \\
\hline & & & $\begin{array}{l}\text { RR: } 5 \mathrm{MP} \\
2560 \times 2048\end{array}$ & $N / A$ & N/A & $\mathrm{N} / \mathrm{A}$ & $1-400$ & 0.170 \\
\hline
\end{tabular}




\begin{tabular}{ll}
\hline Abbreviations & \\
\hline AAPM & American Association of Physicists in Medicine \\
ACR & American College of Radiology \\
AR & $\begin{array}{l}\text { Acquisition room } \\
\text { European Reference Organisation for Quality Assured Breast Screening } \\
\text { and Diagnostic Services }\end{array}$ \\
FFDM & Full Field Digital Mammography \\
IAEA & International Atomic Energy Agency \\
IPEM & Institute of Physics and Engineering in Medicine \\
NHSBSP & National Health Service Breast Screening Programme \\
N/A & Not available \\
\hline RCR & The Royal College of Radiology \\
RM & Reporting Room \\
\hline
\end{tabular}

\section{REFERENCES}

1 Siegel E, Krupinski E, Samei E, Flynn M, Andriole K, Erickson B et al. Digital Mammography Image Quality: Image Display. J Am Coll Radiol 2006;3:615-627.

2 Ong A HJ, Pitman A G, Yi Tan S, Gledhill S, Hennessy O, Lui B et al. Comparison of 3MP medical-grade to $1 \mathrm{MP}$ office-grade $L C D$ monitors in mammographic diagnostic and perceptual performance. J Med Imaging Radiat Oncol 2011;55:153-162.

3 Centre for Reviews and Dissemination University of York. Systematic reviews - CRD's guidance for undertaking reviews in health care. York Publishing Services Ltd, 2009. Available via https://www.york.ac.uk/media/crd/Systematic_Reviews.pdf

$4 \quad$ Whiting P F, Weswood M E, Rutjes A WS, Reitsma J B, Bossuyt P NM, Kleijnen J. Evaluation of QUADAS, a tool for the quality assessment of diagnostic accuracy studies. BMC Med Res Methodol 2006;6:9.

$5 \quad$ Kinnear L, Mercer C E. Blurred lines. A study to compare the detection of visual blurring in $1 \mathrm{MP}$ and $5 \mathrm{MP}$ monitors within mammography clinical practice. Imaging and Therapy Practice 2016;23-28. Available via http://content.yudu.com/Library/A3ylot/ImagingampTherapyPra/resources/23.htm

6 Brettle D S. Display considerations for hospital-wide viewing of soft copy images. Br J Radiol 2007;80:503-507.

7 Chen Y, James J J, Turnbull A E, Gale A G. The use of lower resolution viewing devices for mammographic interpretation: implications for education and training. Eur Radiol 2015;25:3003-3008. 
8 Puchalski S M. Getting the most out of digital image viewing digital viewing. Vet Med 2006;101:14-18.

9 Brennan P C, Murphy P M. Ambient Light Levels for Radiological Soft Copy Viewing: A Multi-Site Comparison. Can J Med Radiat Technol 2007;38:9-13. illuminance on monitor black level luminance and monitor calibration. J Digit Imaging 2003;16:350-355.

11 Pollard B J, Samei E, Chawla A S, Baker J, Ghate S, Kim C et al. The Influence of Increased Ambient Lighting on Mass Detection in Mammograms. Acad Radiol 2009; 16:299-304.

Pollard B J, Chawla A S, Delong D M, Hashimoto N, Samei E. Object detectability at increased ambient lighting conditions. Med Phys 2008;35:2204-2213.

American Association of Physicists in Medicine. Assessment of display performance for medical imaging systems: Executive summary of AAPM TG18 report. Med Phys 2005;32:1205-1225.

14 Van Engen R, Van Woudenberg S, Bosmans H, Young K, Thijssen M. European protocol for the quality control of the physical and technical aspects of mammography screening - Part B: Digital mammography. European guidelines for quality assurance in breast cancer screening and diagnosis. 4th ed. Belgium. 2006;105-166. doi:10.1007/978-3-642-38628-2_100 Available via http://ec.europa.eu/health/archive/ph_projects/2002/cancer/fp_cancer_2002_ext_ guid_01.pdf

15 National Health Service Breast Screening Programme. Guidance on image display equipment for use in breast screening: NHSBSP publication no. 71. December; 2010. International Atomic Energy Agency. Quality Assurance Programme for Digital Mammography IAEA 2011. J Exp Psychol Gen 2011;136:23-42.

17 American College of Radiology. Acr - Aapm - Siim Technical Standard for Electronic Practice of Medical Imaging. 2017;1076:1-18.

18 The Royal College of Radiologists. Picture archiving and communication systems (PACS) and guidelines on diagnostic display devices. 3rd ed. London; 2019. Available via https://www.rcr.ac.uk/system/files/publication/field_publication_files/bfcr192_pacs -diagnostic-display.pdf Institute of Physics and Engineering in Medicine. Recommended Standards for the Routine Performance Testing of Diagnostic X-Ray Imaging Systems IPEM. IPEM Report No. 91, 2005. doi:10.1038/s41413-018-0025-8 
20 Perry N, Broeders M, De Wolf C, Törnberg S, Holland R, Von Karsa L. European guidelines for quality assurance in breast cancer screening and diagnosis. 2013;19:1432 Available via http://www.euref.org/european-guidelines

21 The Royal College of Radiologists. Ergonomics. London: The Royal College of Radiologists, 2012. Available via

https://www.rcr.ac.uk/system/files/publication/field_publication_files/BFCR\%2812 \%297_Ergonomics_0.pdf

22 The Royal College of Radiologists. 35 Audit of Reporting Room Illumination. London: The Royal College of Radiologists, 2013. Available via https://www.rcr.ac.uk/audit/audit-reporting-room-illumination

23 Ma W K, Borgen R, Kelly J, Millington S, Hilton B, Aspin R et al. Blurred digital mammography images: An analysis of technical recall and observer detection performance. Br J Radiol 2017;90:1071 https://doi.org/10.1259/bjr.20160271 